\title{
Urban Soundscape Informational Quantization: Validation Using a Comparative Approach
}

\author{
Philippe Woloszyn", Thomas Leduc ${ }^{2}$ \\ ${ }^{1}$ ESO Lab., Université de Haute Bretagne and CNRS, Rennes, France; ${ }^{2}$ CERMA Lab., ENSA Nantes and CNRS, Nantes, France. \\ Email: philippe.woloszyn@univ-rennes2.fr, thomas.leduc@cerma.archi.fr
}

Received September $1^{\text {st }}, 2010$; revised October $12^{\text {th }}, 2010$; accepted November $17^{\text {th }}, 2010$.

\begin{abstract}
Through interaction with environmental parameters such as light or sound, urban and architectural spaces generate ambiences with identifiable characteristics. This notion of ambiences is related to the human being position through its perception of environmental physical phenomenon during a pedestrian walk. Presented work aims to evaluate, so as to characterize, the impact of sound ambiences (soundscape) onto an urban pedestrian pathway using GIS spatial dynamical mapping. To carry out this scheme, our research work within AMBIOFLUX project concerns spatial interaction between sound ambience (soundscape) and man urban spatial trajectory (soundwalk). Spatial impression of soundsources or soundmarks has to be both defined through acoustical measurement and perception informational evaluation. The remainder of this paper is dedicated to the evaluation's methodology of the pedestrian pathway's acoustic fingerprint using the GearScape spatial formalism described thereafter. Preliminary results we have obtained will also be presented and validated.
\end{abstract}

Keywords: Ambience, Soundscape, Soundmarks, Entropy evaluation, Information dimensioning, GIS semantics

\section{Ambient Environment Perception and Representation}

AMBIOFLUX project concerns spatial interaction between sound ambience (soundscape) and a human urban spatial trajectory (soundwalk). It defines ambiences as an anthropocentric view of the global environmental production through physical, human and built constraints of architectural and urban design. To model it, we consider urban space as a field of data aimed at ambiences physical parameters description through multi-phenomenal characterization [1].

An application of this principle is currently proceeded through this interdisciplinary research project, called AMBIOFLUX, funded by CNRS, French National Centre for Scientific Research, and MEEDDAT Ministry (French Ministry dedicated to Ecology, Energy, Sustainable Development and land use planning) under PIRVE's contract (Programme Interdisciplinaire de Recherche Ville et Environnement). The corresponding research work aims at producing dynamical urban environmental index for spatial interaction indicators between ambience and urban walkthrough [2].

From a software point of view, GearScape (a customi- zation of the OrbisGIS project initially developed by E. Bocher, F. González Cortés and T. Leduc in the CNRS FR 2488 context [3]) original spatial formalism processing aims to qualify pedestrian spatial interactions with producing a set of ambient dynamical indicators.

This approach is therefore founded upon elementary sound sources description, organization and recognition with proceeding to its elementary hierarchic identification and systemic modeling [4,5].

\section{Soundmarks as Soundscape Psychophysical Encoded Elements}

Soundscape informational dimensioning will be considered through urban sound sources spatial psychophysical indicators formulation, soundmarks. Murray Schäfer introduces the word "soundmarks" as a derivation of the word "landmark", to identify sounds which sign the outstanding role of sounds to characterize a place [6]. In this sense, soundmarks describe sound events which get a specific informational status, mainly denotative, that means they are strong identity revealers.

The dedicated informational order scaling corresponds to near-order indices, which can be evaluated through maximal information entropy. Therefore, soundmarks are 
defined as maximum-entropy sources a soundwalker can meet, defined as the most consciously emerging urbansituated events within his world-line, for a given urban trajectory. They are computed using local entropy sources calculation $\mathrm{H}$ [7], as described in Equation (2).

\subsection{Worldline as a Soundwalk Representation Model}

For the pedestrian who wanders around the urban space, the ambient phenomenon overlapped with the ur- ban landscape might be considered as a marker of the entire phenomenon distributed around a place, creating a perceptible atmosphere for anybody located in this space [8].

The fundamental principle of the world-line considers the temporal structure of perception, claiming that an observer identifies the beginning and the end of a perceived event. This assumption states that the observer codes its corresponding time-segment, or world-line, as a causal attribute of the perceived event $[10,11]$. In our case, for a given subject and within a given observation period, soundscape knowledge of an observer is relevant to sound sources emergence and occurrence frequency. Those two subjective characteristics constitute the main scaling dimensions which have to be defined for informational quantization.

\subsection{Entropy Index Dimensioning}

Among various variables, the entropy is the thermo dynamical simplest quantity to be applied to non-physical systems, as it is considered to be a measure of system disorder within informational datasets.

Unlike thermodynamic entropy, being a "content-full" concept specific to thermodynamic systems, statistical entropy applied here qualifies informational probability distribution as a "content-free" syntactic concept, a quantity calculated from the numerical properties of the "virtual system" distribution laws.

It is important to note that even Boltzmann's view of the second law of thermodynamics, using the entropy term [12] as a law of disorder into an open system, confirms this "content-free" ontological status of statistical entropy [13].

Following this assumption, the challenge of the work pioneered by Shannon and Jaynes $[14,15]$ was to extend the entropy concept and to apply its measure in as many different contexts as possible.

Therefore, Shannon's information theory [14] together with E.T. Jaynes principle of Maximal Entropy [15] provides a constructive criterion for setting up probability distributions on the basis of partial knowledge. This criterion leads to a statistical inference model called maximum-entropy estimate.

\subsection{Application: Soundscape Entropy Quantification}

Sound source geo-localization (xy location into the urban maze), is gathered here with two spatial extends: sound pressure level and soundmark entropy values.

Equivalent Sound Level is formulated in terms of the equivalent steady noise level which in a stated period of time would contain the same noise energy as the time varying noise during the same time period [16]:

$$
L_{e q}=10 \times \log \left(\frac{1}{T} \sum_{i} 10^{L_{e q i}} / 10 \times \Delta T_{i}\right)
$$

The second indicator corresponds to Shannon entropy calculation [14] as:

$$
H=\sum_{x \in X} p(x) \log \frac{1}{p(x)}
$$

which describes the uncertainty quantity by the information which we do not have about the state occupied by the concerned source.

Probability $p(x)$ is based on empirical frequencies measurement issued from observation statistics from inquiries and soundwalkers expressions [17], and is actually calculated from the frequency occurrence of the related event $x$ within the recorded soundscape; Huffmann's perceptual encoding can then be enacted through the relevant soundscape Zipf-Pareto law for the sources distribution [18].

The resulting quantity is a measure of the uncertainty of the soundscape events occurrence: the higher the $\mathrm{H}$ value, the more unpredictable the constitutive sound events; in other words, entropy index $H$ constitutes a reliable soundscape originality measurement.

In our case, Maximum Entropy principle considering n sound sources as discrete random variables $x_{i}$ with entropy $H_{i}$, the "largest remaining uncertainty probability distribution" can be estimated from the $2^{\mathrm{n}-1}$ dimensional vector, called entropy vector $E(x)$, following equation (3) formulation:

$$
E(x)=\frac{1}{n} \sum_{i=1}^{n}-\log p\left(x_{i}\right)=\operatorname{Max}\left\{H_{1}, \cdots, H_{n}\right\}
$$

This quantity helps to study the behavior of the information taking into account the $\mathrm{n}$ sources composing the studied soundscape. The related quantity $E(x)$ gives us the extension value of the corresponding soundmark, considering its ability to reach the listener (source emergence value) during the corresponding urban soundwalk.

For a given soundscape, sensation scaling proceeds 
from "soundmarks" (maximum entropy sound event) to "Keynotes" (null-entropy background noise) [19].

\subsection{Zipf-Pareto Law Sources Distribution Dimensioning}

First applied for English texts word occurrence frequency determination, empirical law known as "Zipf law", named for Harvard linguistic professor George Kingsley Zipf, models the occurrence of distinct objects in particular collections [20-23]. Zipf law says that the $\mathrm{i}^{\text {th }}$ most frequent object will appear $1 / \mathrm{i}^{\text {th }}$ times the frequency of the most frequent object in the collection. Moreover an expression of universal regularities, this law is applied in numerous domains: in English texts word occurrence frequency $[20,24,25]$, as well as populations of cities [26-28], immune system characterization [29], bibliographical classification or prediction [30,31], or cancer classification [32]. Nevertheless, except musical [33-35] and audio medical signal [36] applications, we did not find Zipf law application for other audio domains such as soundscape acknowledgment in scientific literature.

Zipf's law may be stated mathematically as:

$$
\log \left(f_{x}\right)=C-s \times \log (k)
$$

where $f_{x}$, the frequency of the unit (word form or lemma) having the rank $k, s$, the exponent coefficient (near to 1 for French language word frequency distribution), and $C$, a constant.

For soundscape application, mathematical expression of Zipf law involves the number of occurrences of a done sound source, understood as an acoustic emerging event. Within a given soundscape, relationship between the constitutive sound sources emegence with respect to their occurrence frequencies should then provide a rank-order Zipf power law, with a specified entropy dependent slope. The resulting event density probability distribution will then provide information quantification through entropy indexing, thanks to the use of GearScape dedicated spatial semantic system.

\section{Soundscape Geoprocessing}

The main idea here is to take benefit from Geographical Information well-known concepts and techniques and apply them both to the spatial interactions between sound ambiances and an urban pedestrian walk. Therefore, we have to map soundmarks effects onto the pedestrian pathways and compute some relevant indicators to characterize the environmental interaction process. Among all of them, we have decided to focus on the spatial sound pressure integrated levels and the entropy index. The main add-on of this paper is clearly to couple soundscape emergence concept with a pedestrian mobility, that is to say a dynamic process. Confluence is achieved in the context of a specific Geographical Information System called GearScape.

The data that have to be processed are purely of vector type. They are provided by the French IGN agency (lay- ers extracted from the so called BD ORTHO ${ }^{8}$ spatial database). The study areas have been selected because of their wide morphological variabilities concerning both the urban fabric and the corresponding networks.

As illustrated in Figure 1, the global spatial process we have designed concerning the Strasbourg use case is divided into 10 main steps combining some well-known OGC $[38,39]$ functions. It consists in a sort of raster approach, which relies on an orthogonal regular grid based layer produced using an operator developed in the context of the UrbSAT plugin [40,41].

Unlike to the 1st approach, the 2nd one develops a rather different method (see Figure 2). Instead of meshing the surrounding soundscape it discretizes the soundwalks themselves. This processing schema is much more robust and efficient. This is the one we have adopted with the Nantes town centre use case.

\section{Comparative Case Studies}

\subsection{Contexts}

In this section we will successively apply and detail all the processes presented in Section 3 to one of the main study area of the AMBIOFLUX project in Strasbourg suburbs and to the Nantes city center. First case study is located in the north suburbs of the French city Strasbourg (see Figure 3). It corresponds to a rectangular area of less than $2.9 \mathrm{~km}$, from north to south, by $2.2 \mathrm{~km}$, from west to east. In this region of interest, 5 different pedestrian pathways are defined with an average length of 4.7 $\mathrm{km}$ and a standard deviation equals to $1.2 \mathrm{~km}$. All those pathways connect Schiltigheim city to Strasbourg's railway station.

In addition to input data already mentioned, 7 soundmarks have been defined. In all corresponding locations, sound recording have been performed and analyzed for the 5 more significant ones.

After recording operation, qualitative analysis consists in operating a multi-sources description of the whole sequence. A statistic of the resulting description items will then provide their respective occurrence frequencies, in order to be plotted regarding their corresponding emergence levels.

Thereafter, a rank-order (Zipf) analysis has been processed taking each constitutive source within the sound marked sequence into account.

Second case study is located in Nantes historic heart, a 


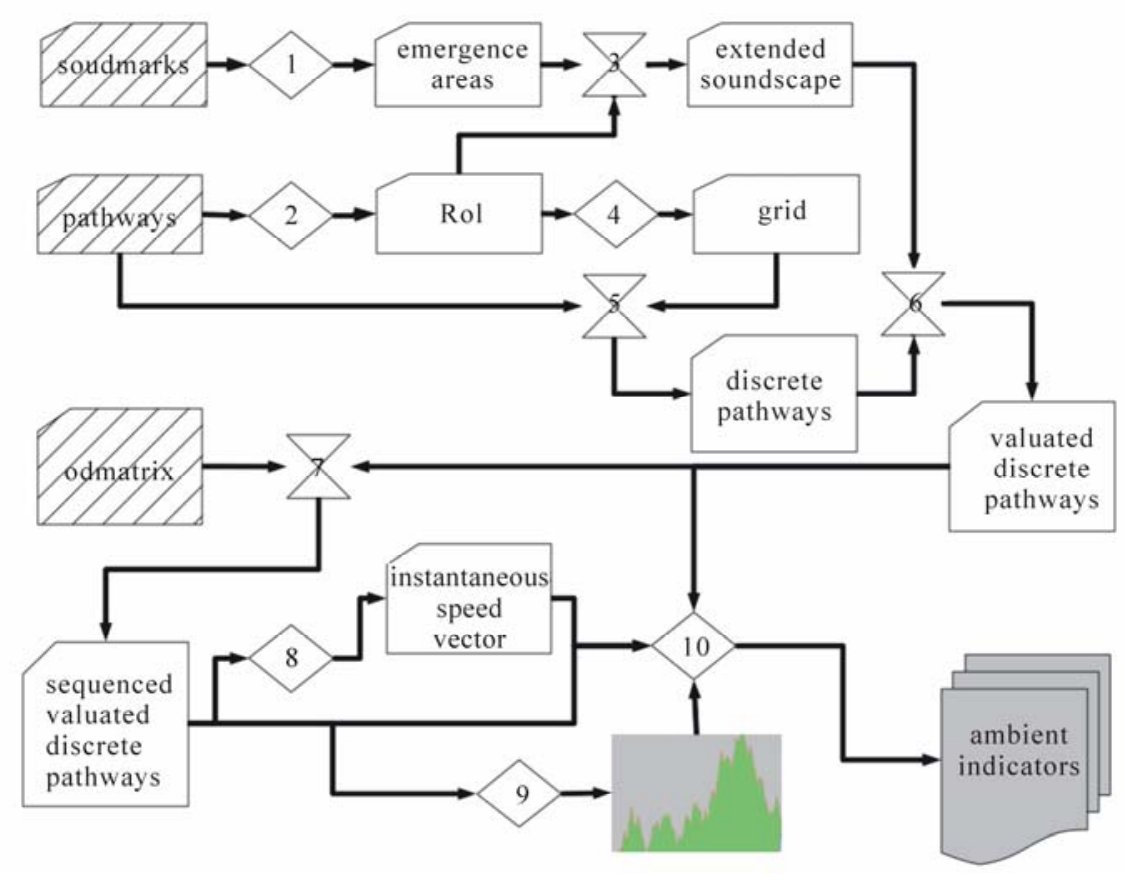

Figure 1. The processing schema we have adopted in the Strasbourg use case. The sequence is composed of 10 main operations. Input maps are 45 degrees wide hatched, intermediate results have no background color and final output results are colored in gray.

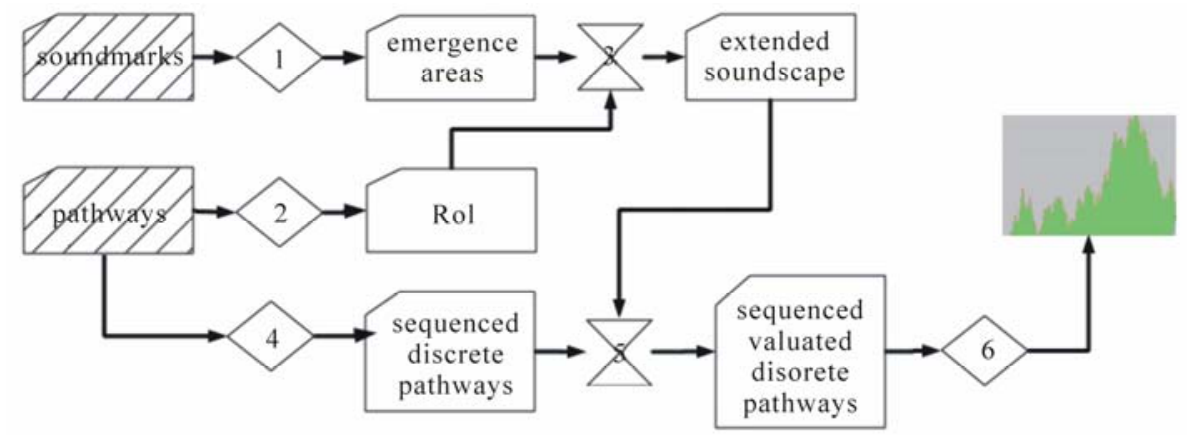

Figure 2. The processing schema we have adopted in the Nantes use case. The sequence is composed of 6 main operations. Input maps are 45 degrees wide hatched, intermediate results have no background color and final output results are colored in gray.

west-coast located city in France (see Figure 4). Walks were led the same day evening, from town-hall to Roosevelt Court. The fourteen fixed recording sequences points have then been analyzed to compute Zipf rankorder analysis and calculate the corresponding entropy values. The high density of analyzed points will enable a fine spatial discretization for soundmarks entropy evaluation, according to the perceived sources occurrence frequencies.

\subsection{Results and Discussion}

As illustrated by the low Zipf rank-order slope values of the Figure 5, emergence density probability distribution of the recorded points clearly discriminates poor soundscapes ("low-fidelity" soundscapes in the sense of $\mathrm{M}$. Schäfer [6,19], corresponding here to points 1 (Rempart) and 3 (Autoroute de l'Est)), from rich ones ("high-fidelity" soundscapes, composed with hierarchized numerous sound sources, corresponding here to points 5 (Cité Nucléaire), 6 (Schiltigheim) and 7 (Z. A. Mittelfeld)). As a result, we obtain a set of spatial punctual positions and, for each of them, ambient indicators such as the aggregated $L_{\text {eq }}$, coupled together with entropy evaluation. The numerical values we obtain are presented in Figure 7.

To characterize each studied pedestrian pathways, some ambient indicators are produced such as the aggregated 


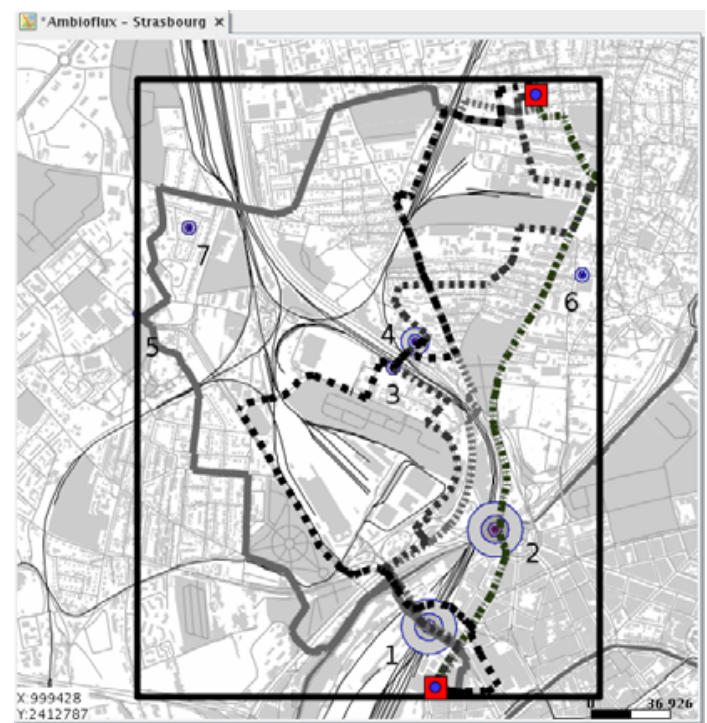

Figure 3. Zoom on the Region of Interest located in the north-west of the French city Strasbourg. All pedestrian pathways (dotted polylines) share the same origin (disc in a square, north of the map) and destination (disc in a square, south of the map) points. The seven soundmarks emergence areas are numbered and represented by pale gray concentric discs.

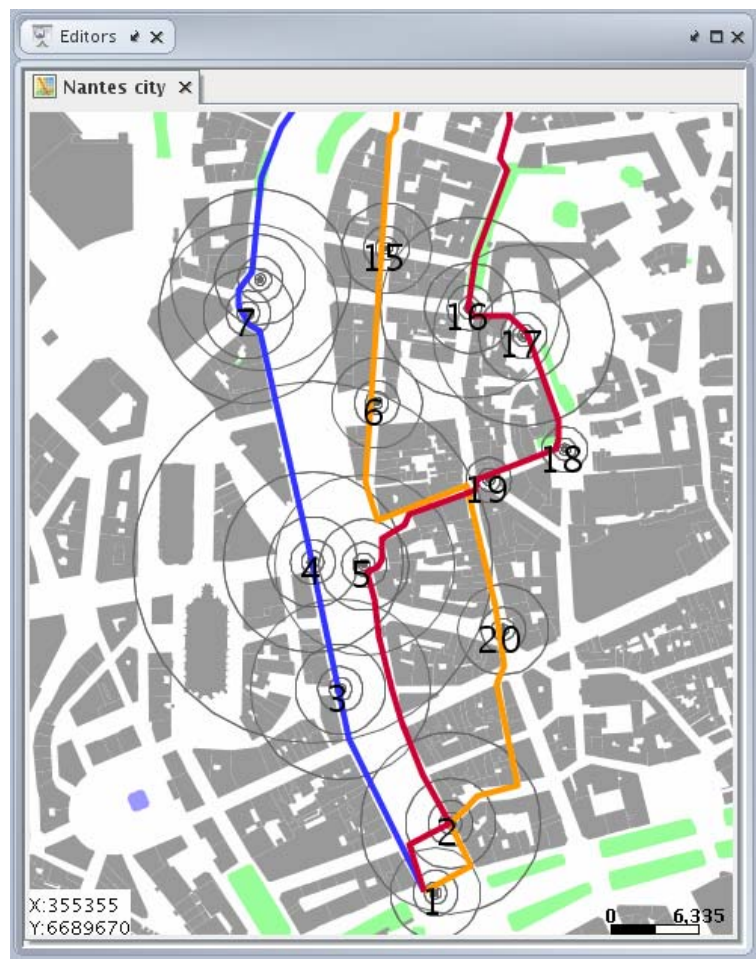

Figure 4. Zoom on the Region of Interest located in the town center of the French city Nantes. All pedestrian pathways share the same origin (north of the map) and destination (south of the map) points. The 14 soundmarks emergence areas are numbered and represented by concentric discs.
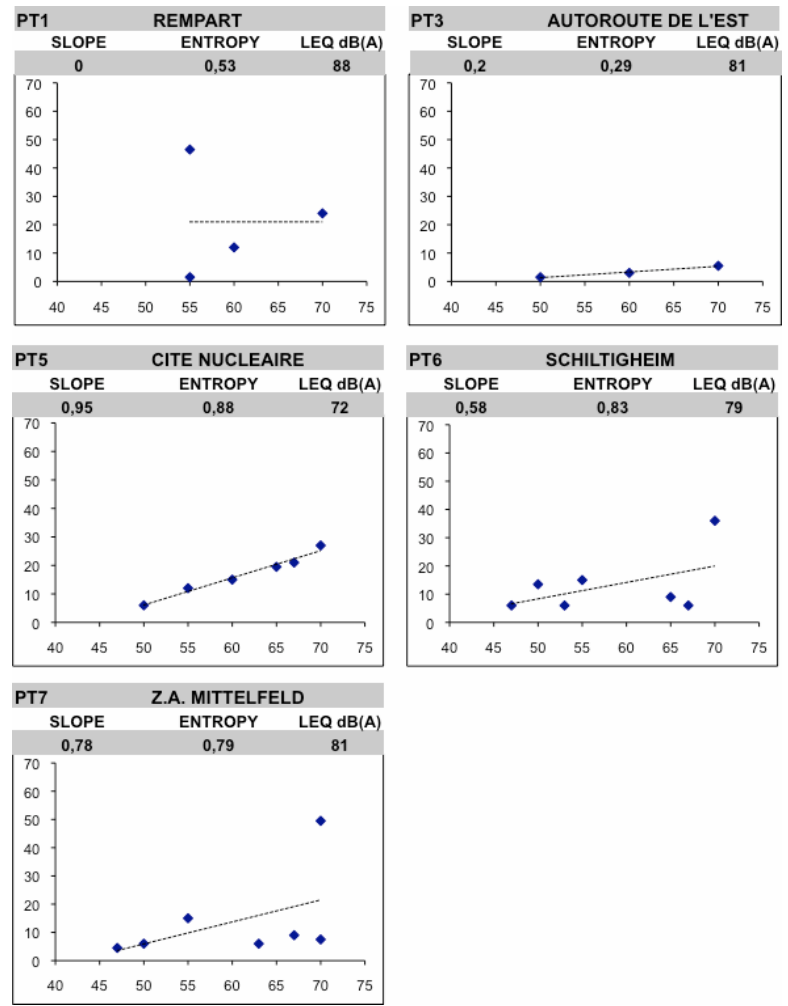

Figure 5. Zipf rank-order laws, entropy values and sound levels for soundwalk points in Strasbourg suburbs.

Leq or the maximum entropy value all along the pathway.

Concerning Nantes's walkthrough area, calculated entropy values (see Figure 6) clearly discriminate three sets of soundmarks: a "low entropy group", scaling values from 0.6 to 0.7 (points 3,4,8 and 15), a "middle" one, with entropy values from 0.7 to 0.8 (points $1,2,6,7$, and 17) and a "high entropy group" gathering values over 0.8 (points 16,18,19,20). One can note that this values distribution is confirmed by the soundmarks Zipf rank-order laws, which regression values scales from 0.02 to 0.29 for the first group, from 0.2 to 0.5 for the second one, and from 0.4 to 0.5 and more for the "highest entropy group".

Another remark concerns the relatively lower entropy values bracket for Nantes soundmarks, compared to Strasbourg's ones. This fact can be explained by the difference of areas extensions: since Strasbourg's area, dedicated to seven urban soundwalks analysis is about 6 $\mathrm{km}^{2}$, Nantes area study gather fourteen points in about only $0.7 \mathrm{~km}^{2}$. Consequently, high soundmarks density within this last area, concentrated in a relatively homogeneous urban district, can not offer the same sound ambience variations than the first one in Strasbourg.

As may be noticed, paths number 2 to 5 (see Figure 3) 

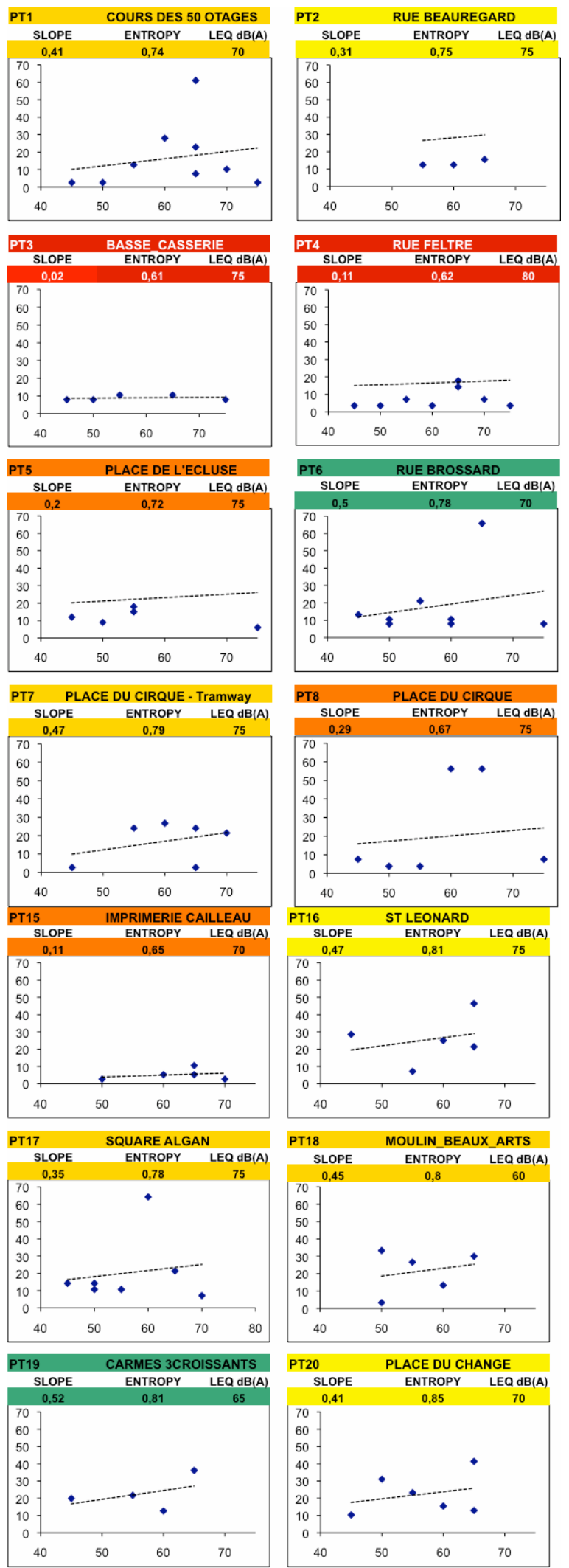

Figure 6. Zipf rank-order laws, entropy values and sound levels for soundwalk points in Nantes city center.

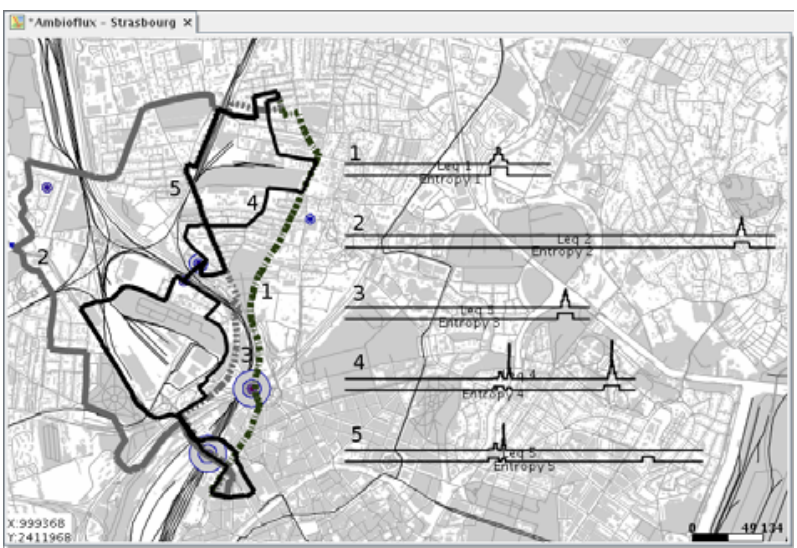

Figure 7. Time-line approach of the equivalent sound level and the entropy index of Strasbourg suburbs.

share the same maximum entropy value. It is due to the fact that they all come across the same predominant soundmark (south-most one, tagged as "Rempart").

What seems important to notice here is that both entropy and equivalent sound level signatures do not fully match in the particular case of the 5th pathway (see Figure 7). Indeed, crossing half the first soundmark emergence area (south-most one, tagged as "Rempart"), the "soundwalker" faces a particular acoustic event that is not significant in term of noise energy but in term of informational content (entropy). This clearly shows that entropy index is not strictly correlated with the equivalent sound level index.

For Nantes city centre area, informational treatment exposed in Figure 8 provides a time-sliced discreet quantitative information on the soundscape originality and intelligibility of the concerned sound environment during the walks. Thus, the "distance gap" between soundmarks (observation points) has to be well-dimensioned to obtain a continuous varying entropy signal. As observed here, a relatively dense soundmarks discretization within the urban space allows a quasi-coherent entropy signal along the soundwalk pathways.

\section{Validation Method: Entropy vs. Soundscape Multi-Sources Combination}

\subsection{Reference Model Presentation}

In order to evaluate the stability of our method, we have decided to compare the results we obtained on the city of Nantes with an already published soundscape quality map. This map was aimed to produce sonic ambiance's compositions during a soundwalk, constitutes a unique attempt of sound ambiance qualitative analysis in scientific literature by Léobon in the 90's [45]. This structural and phenomenological approach of Nantes city soundscape is based on environmental sources sonic signatures 


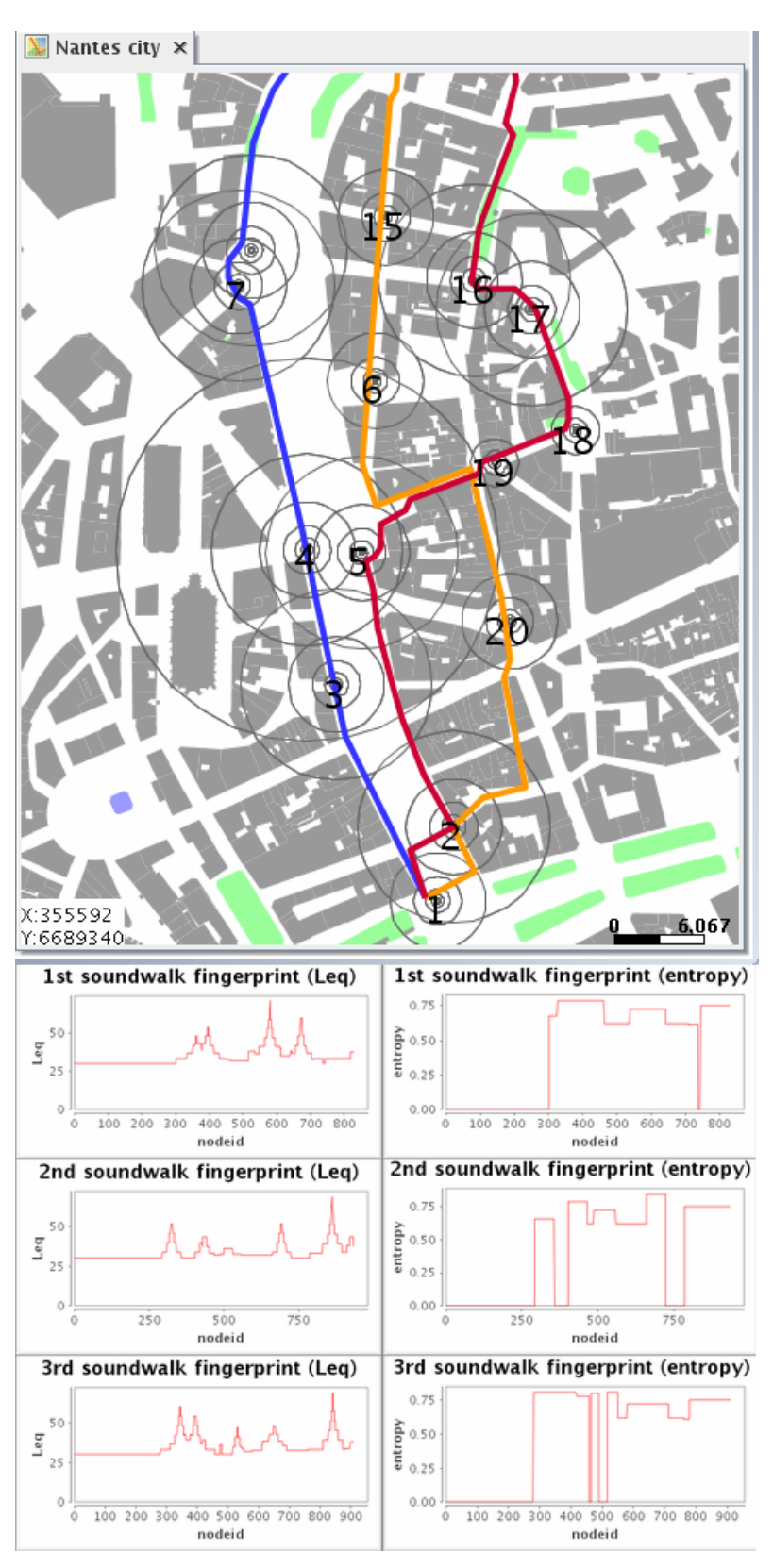

Figure 8. Time-line approach of the equivalent sound level and the entropy index of Nantes city center (The 1st soundwalk is blue colored, the 2nd one is orange colored, the 3rd one is red colored).

analysis.

In this approach, “environmental sound sources” composing our perception of the urban landscape are translated into descriptive items, which statistical analysis leads to a soundscape multisources cartography.

This reference qualitative sonic inventory is fed with urban soundwalks, marked out by relevant recording points, short sound sequences representing rather faith- fully the districts' various sonic atmospheres. Sampling of this soundwalk is relevant to an exploration process, discretizing urban space through obvious soundscape changes.

Each recorded sequence, examined through headphone listening, is transcribed into a list of sonic items, grouped together according to sound sources families, thus constituting a hierarchic structure between three extreme uses of public spaces (as shown in Figure 9): the pedestrian sequence function ("Présence" in blue), the traffic line function (“Activité Mécanique” in red), and the animated places ("Animation" in yellow).

The cartographic mapping we reefers to associates a dedicated color to the corresponding area for each recording point within the soundwalks, according to the soundscape multi-sources composition. The ten colours used to represent the various sonic atmospheres of a city centre are the following (see Figure 10):

1) Blue: pedestrian, open spaces or residential sonic areas;

2) Purple: open spaces sonic areas with traffic noise in the background;

3) Green: mixed sonic areas with dominant anthropogenic noise;

4) Light green: mixed sonic areas with predominant anthropogenic noise, moderately animated;

5) Yellow: intensely animated sonic areas;

6) Salmon pink: mixed sonic areas with pedestrian and road traffic, without sonic signs of activity;

7) Light yellow: mixed sonic areas with pedestrian and road traffic, moderately animated;

8) Orange: mixed sonic areas with dominant road traffic noise;

9) Ochre: mixed sonic areas with dominant road traffic noise, animated;

10) Red: predominant road traffic noise.

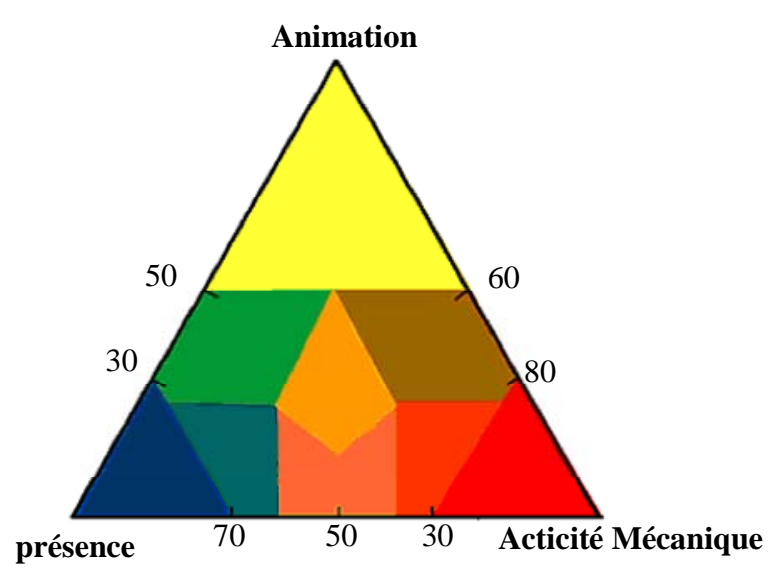

Figure 9. Sound sources color trade-off (extracted from [45]). 
Ambiances sonores piétonnes, paysagères ou résidentielles

Ambiances sonores paysagères ou résidentielles sur bruit de fond circulé

Ambiances sonores mixtes à dominante humaine

Ambiances sonores mixtes à dominante humaine relativement animées

Ambiances sonores très animées

Ambiances sonores mixtes "piétonnes et circulées"

Ambiances sonores mixtes et animées

Ambiances sonores mixtes à dominante circulée

Ambiances sonores mixtes à dominante circulée avec animation

Ambiances sonores très circulées

Figure 10. The ten colors used to represent the various sonic atmospheres of a city centre (extracted from [45]).

\subsection{Ambient Multi-Sources Informational Validation}

The Nantes entropy and Zipf rank-order law calculations were produced with strictly the same points used for the reference sound ambience cartography we will present now. As we were part of this research [46], we used the same audio samples to provide the previous informational computing: this enables direct comparisons between originality measurement (informational computing) and ambient multi-sources characterization (Léobon's methodology [47]).

The reference cartographic representation uses the previously described colors to indicate the composite multi-sources areas, as seen on the following sound ambience map, based on Léobon's summer evening soundwalks in Nantes city center (see Figure 11) [48].

Despite their short extends, those paths reveal various atmospheres that a passer-by would face when wandering in the urban maze. As a consequence of this case study limited area, the great density of analyzed points enables a very fine qualitative discretization of the paths for micro-structural analysis of the soundwalks.

\subsection{Results Comparison: Entropy Values vs. Ambiance Multisource Qualification}

In order to validate the maximum entropy values obtained all along the three pathways, we will compare them to the soundscape ambient multi-sources data, presented in the sound ambiences cartography Figure 11 above. To facilitate this data set comparison, we have reused the color code already presented. Thus, in the Table 1, each row color corresponds to the characteristic of the corresponding soundmark.

In this case study, poor soundscapes correspond to red (areas with predominant road traffic noise) and orange (mixed areas with dominant road traffic noise) colors. Their respective entropy values scale from 0.61 to 0.75 for all the concerned points (points 1, 3, 4, 5, 8, and 15). A common characteristic of all those punctual positions is their high road traffic noise component, which tends to "annihilate" the other sound sources, and impoverish the

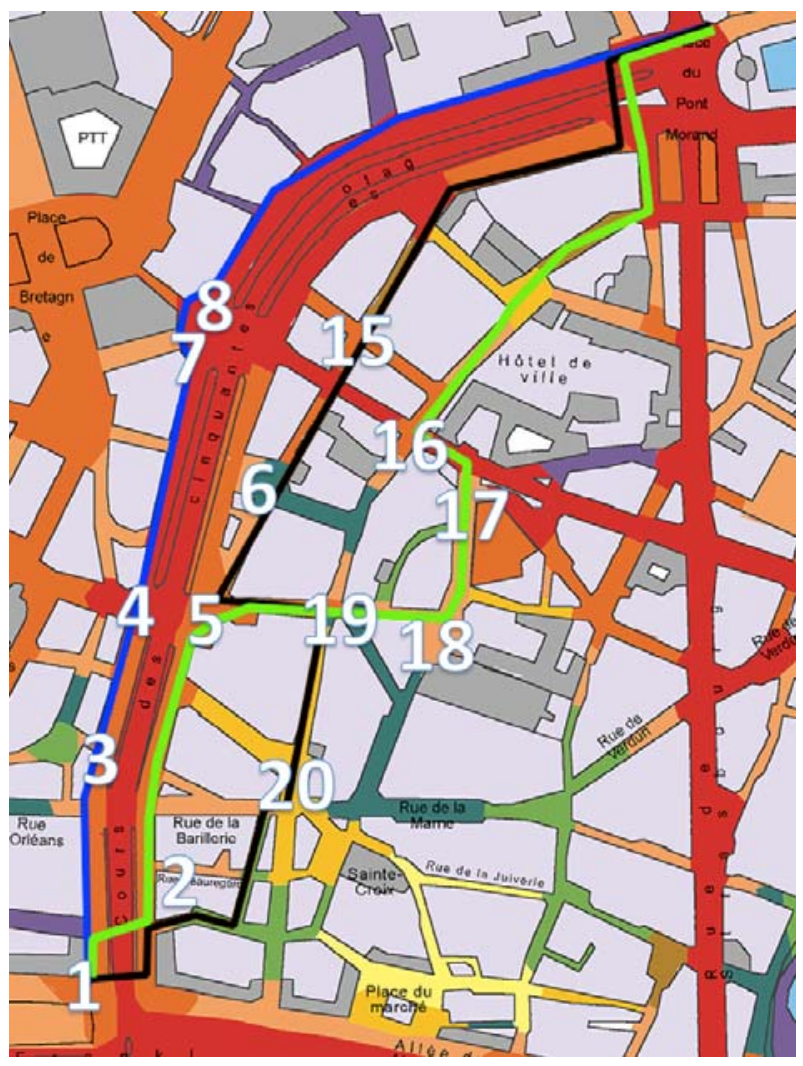

Figure 11. The Nantes city center sound ambiences on summer evening [48], including the 3 soundwalks paths and the recording punctual positions. 
Table 1. Soundmarks attributes (Nantes' use case). Comparative table between the soundmarks informational characterization, multisource composition and sound levels. Color coding is refeering to the sound ambience cartography (see Figure 11).

\begin{tabular}{|c|c|c|c|c|}
\hline PT & SLOPE & ENTROPY & $\begin{array}{c}\text { AMBIANCE } \\
\text { DESCRIPTION }\end{array}$ & $\begin{array}{r}\text { LEQ } \\
\mathrm{dB}(\mathrm{A})\end{array}$ \\
\hline 1 & 0.41 & 0.74 & $\begin{array}{l}\text { Pedestrian and road } \\
\text { traffic }\end{array}$ & 70 \\
\hline 2 & 0.31 & 0.75 & $\begin{array}{l}\text { Pedestrian, road } \\
\text { traffic and animated }\end{array}$ & 75 \\
\hline 3 & 0.02 & 0.61 & $\begin{array}{l}\text { Predominating road } \\
\text { traffic noise }\end{array}$ & 75 \\
\hline 4 & 0.11 & 0.62 & $\begin{array}{l}\text { Predominating road } \\
\text { traffic noise }\end{array}$ & 80 \\
\hline 5 & 0.2 & 0.72 & $\begin{array}{l}\text { Mixed with dominant } \\
\text { road traffic }\end{array}$ & 75 \\
\hline 6 & 0.5 & 0.78 & $\begin{array}{l}\text { Mixed with dominant } \\
\text { human noise }\end{array}$ & 70 \\
\hline 7 & 0.47 & 0.79 & $\begin{array}{l}\text { Pedestrian and road } \\
\text { traffic }\end{array}$ & 75 \\
\hline 8 & 0.29 & 0.67 & $\begin{array}{l}\text { Mixed with dominant } \\
\text { road traffic }\end{array}$ & 75 \\
\hline 15 & 0.11 & 0.65 & $\begin{array}{l}\text { Mixed with dominant } \\
\text { road traffic }\end{array}$ & 70 \\
\hline 16 & 0.47 & 0.81 & $\begin{array}{l}\text { Pedestrian, road } \\
\text { traffic and animated }\end{array}$ & 75 \\
\hline 17 & 0.35 & 0.78 & $\begin{array}{l}\text { Pedestrian and road } \\
\text { traffic }\end{array}$ & 75 \\
\hline 18 & 0.45 & 0.8 & $\begin{array}{l}\text { Pedestrian and road } \\
\text { traffic }\end{array}$ & 60 \\
\hline 19 & 0.52 & 0.81 & $\begin{array}{l}\text { Mixed with dominant } \\
\text { human noise }\end{array}$ & 65 \\
\hline 20 & 0.41 & 0.85 & $\begin{array}{l}\text { Pedestrian, road } \\
\text { traffic and animated }\end{array}$ & 70 \\
\hline
\end{tabular}

corresponding soundscapes. Moreover, those points are characterized with high sound pressure levels (around 75-80 dB(A)).

On the other side, soundscape richness is signed up with higher entropy values: the corresponding punctual positions display entropy values from 0.75 to 0.85 (points 2, 6, 7, 16, 17, 18, 19, and 20), signing more "anthropogenic" or "animated" soundscapes, as "pedestrian, road traffic and animated areas" (light yellow color coded), or "mixed areas with dominant human noise" (light green). Sound level values of those points are mostly lower (around 65-70 dB(A)).

\subsection{Discussion}

Considering this sharp fitting between soundscape multisource characterization and their entropy evaluation, this approach allows to characterize soundscape originality in terms of "phonicity", measuring the intelligibility of a soundscape, which is our ability to identify all its components. Moreover, we can notice that a noise level's map would fail to provide information as accurate about a district's sonic identity. The comparison between noise and entropy levels of the same sonic walk shows without contest that only this last can be able to discriminate very close sonic ambiences, taking both vehicle's traffic and pedestrian activity into account.

\section{Conclusions}

Reference map scales the gradual intensity variation of a sound quality in terms of soundscape multisource composition. This composite sound qualitative hierarchy, which human mind may express through an ordering scale, can be traduced by Zipf rank-order power law.

Next step of our work will study the entropy signal shape, more precisely its "remanence" component, which means the "memory effect" of soundmarks. This will enable to consider soundmark effect as a "non instantaneous" process (actually traduced through a squared entropy signal when the listener is entering the soundmark influence disc), with considering an "entropy decay" when the soundwalker leaves the soundmark influence zone. Computation of this decay will be stated from the Zipf rank-order power law, considered as a $1 / \mathrm{f}$ sound source density distribution, in order to calculate a "soundmark emergence power spectrum", able to provide a soundwalk continuous informational evaluation.

\section{Acknowledgements}

The AMBIOFLUX project was funded by CNRS, French National Center for Scientific Research, and MEEDDAT Ministry (French Ministry dedicated to Ecology, Energy, Sustainable Development and land use planning) under PIRVE's contract (Programme Interdisciplinaire de Recherche Ville et Environnement).

Part of the GearScape software development was funded by the AMBIOFLUX project.

\section{REFERENCES}

[1] P. Woloszyn, "From Fractal Techniques to Subjective Quantification,” In: Landscape and Architectural Modelling Symposium Proceedings, Sousse, pp. 1-6, 2002.

[2] P. Woloszyn and D. Follut, "The Visualisation of the Urban Ambients Parameters," Computer Science for Environmental Protection, Gesellschaft für Informatik (GI), Bonn. Marburg (DE): Metropolis Verlag, 2000, pp. 173186.

[3] T. Leduc, F. González Cortés and E. Bocher, “OrbisGIS: a GIS for Scientific Simulation,” In: RMLL'2007, Amiens, France, 2007.

[4] J. J. Gibson, "The Ecological Approach to Visual Perception,” Hillsdale, New Jersey, 1986.

[5] K. Richardson, "Hyperstructure in Brain and Cognition," psyc.99.10.031, 1999.

[6] R. M. Schäfer, “The Tuning of the World,” Knopf, New York Republished in The Soundscape: Our Sonic Environment and the Tuning of the World, Rochester, Vermont: Destiny Books, 1977. 
[7] P. Woloszyn and G. Bourdin, "Urban HyperScape: A Community Game for Territorial Knowledge,” In: Second International Annual Conference of Territorial Intelligence, Huelva (Spain) October 24th-27th, 2007, Observatorio Local de Empleo, Huelva, pp. 219-242.

[8] P. Woloszyn and G. Bourdin, “The Hyperscape Project: Participative Game Informational Construction,” 6th Annual International Conference of Territorial Intelligence, Besançon, 2008.

[9] A. A. Moles, "Théorie Structurale de la Communication et Société,”Paris, Masson/CNET/ENST, 1988, p. 295.

[10] R. G. Barker, "Structure of the Stream of Behavior," Proceedings of the 15th International Congress of Psychology, 1957, pp. 155-156.

[11] R. G. Barker, "The Stream of Behavior as an Empirical Problem,” The Stream of Behavior, New York, Appleton of Century Crofts, 1963, pp. 1-22.

[12] D. A. Salvo, "Boltzmann and Hertz on the Bild- conception of Physical Theory," History of Science, Vol. 28, No. 79, 1990, pp. 380-398.

[13] K. D. Bailey, "Social Entropy Theory: An Application of Nonequilibrium Thermodynamics in Human Ecology," Advances in Human Ecology, Vol. 2, 1993, pp. 133-161.

[14] C. E. Shannon and W. Weaver "The Mathematical Theory of Information Urbana,” University of Illinois Press, 1949.

[15] E. T. Jaynes, "Where do We Stand on Maximum Entropy?” The Maximum Entropy Formalism, Raphael D. Levine and Myron Tribus, editors, The MIT Press, Cambridge, MA, 1979, pp. 15-118.

[16] EPA (U. S. Environmental Protection Agency), "Information on Levels of Environmental Noise Requisite to Protect Public Health and Welfare with an Adequate Margin of Safety,” EPA/ONAC 550/974004 Washington, D.C., 1974.

[17] P. Woloszyn, "An Acoustic Ambience Study by Immersive Sound Recognition,” European Conference Building with Sounds, Paris, March 2005.

http://rp.urbanisme.equipe-ment.gouv.fr/puca/agenda/DA FAG_WoloszynA_170305.pdf

[18] G. K. Zipf, "Human Behaviour and the Principle of the Least Effort,” Addison-Wesley, Reading, 1949.

[19] R. M. Schafer, "Music, Non-Music and the Soundscape," Companion to Contemporary Musical Thought, Vol. 1, Paynter, J. Howell, T. R. Orton and P. Seymour, (ed.'s) (Routledge), 1992.

[20] G. K. Zipf, "Selected Studies of the Principle of Relative Frequencies of Language," Cambridge, Massachusetts: Harvard University Press, 1932.

[21] B. C. Brookes, "The Derivation and Application of the Bradford-Zipf Distribution,” Journal of Documentation, Vol. 24, No. 4, 1968, pp. 247-265.

[22] L. Egghe, “The Exact Place of Zipf's and Pareto’s Law amongst the Classical Information Laws,” Scientometrics, Vol. 20, No. 1, 1991, pp. 93-106.

[23] M. Kunz, M. Lotka and G. K. Zipf “Paper Dragons with
Fuzzy Tails,” Scientometrics, Vol. 13, No. 5-6, 1988, pp. 289-297.

[24] D. C. Blair, "Language and Representation in Information Retrieval,” Amsterdam, Elsevier, 1990.

[25] W. Li, "Random Texts Exhibit Zipf's-Law-Like Word Frequency Distribution,” IEEE Transactions on Information Theory, Vol. 38, No. 6, 1992, pp. 1842-1845.

[26] X. Gabaix, “Zips's Law for Cities: An Explanation,” Quarterly Journal of Economics, Vol. 114, No. 3, 1999, pp. 739-767.

http://econ-www.mit.edu/faculty/download_pdf.php?id=5 30 .

[27] R. Kali, "The City as a Giant Component: A Random Graph Approach to Zipf's Law,” Applied Economics Letters, Vol. 10, No. 11, 2003, pp. 717-720.

[28] K. T. Soo, “Zipf's Law for Cities: A Cross Country Investigation, Mimeo," An Updated Version has been Published in 2005 in Regional Science and Urban Economics Vol. 35, No. 3, 2002, pp. 239-263.

[29] J. D. Burgos and P. Moreno-Tovar, "Zipf-Scaling Behavior in the Immune System,” Biosystems, Vol. 39, No. 3, 1996, pp. 227-232.

[30] R. A. Fairthorne, "Empirical Hyperbolic Distributions (Bradford-Zipf-Mandelbrot) for Bibliometric Description and Prediction,” Journal of Documentation, Vol. 25, No. 4, 1969, pp. 319-343.

[31] J. Fedorowicz, “The Theoretical Foundation of Zipf's Law and its Application to the Bibliographic Database Environment," Journal of the American Society for Information Science, Vol. 33, No. 5, 1982, pp. 285-293.

[32] W. Li and Y. Yang, "Zipf's Law in Importance of Genes for Cancer Classification Using Microarray Data,” Journal of Theoretical Biology, 2002, pp. 539-551.

[33] B. Manaris, T. Purewal and C. McCormick, "Progress Towards Recognizing and Classifying Beautiful Music with Computers: MIDI-Encoded Music and the Zipf-Mandelbrot Law," Proceedings of the IEEE SoutheastCon 2002, New York: Institute of Electrical and Electronics Engineers, 2002, pp. 52-57.

[34] B. Manaris and Alii, "Zipf's Law, Music Classification, and Aesthetics," Computer Music Journal, Vol. 29, No. 1, 2005, pp. 55-69.

[35] B. Manaris et al., "Evolutionary Music and the Zipf-Mandelbrot Law: Progress towards Developing Fitness Functions for Pleasant Music," Proceedings of EvoMUSART2003-1st European Workshop on Evolutionary Music and Art, Berlin: Springer-Verlag, 2003, pp. 522534.

[36] E. Dellandréa, P. Makris and N. Vincent, “Zipf analysis of Audio Signals,” Fractals Vol. 12, No. 1, World Scientific Publishing, Singapore, 2004, pp.73-85.

[37] B. Mandelbrot, "Information Theory and Psycholinguistics,” R. C. Oldfield and J. C. Marchall, Eds., Language, Penguin Books, 1968.

[38] J. R. Herring, “OpenGIS ${ }^{\circledR}$ Implementation Specification for Geographic information - Simple Feature Access-Part 
1: Common architecture,” 2006.

http://www.opengeospatial.org/standards/sfs

[39] J. R. Herring, “OpenGIS® Implementation Specification for Geographic Information - Simple Feature Access Part 2: SQL option,” October 2006.

http://www.opengeospatial.org/standards/sfs

[40] N. Long, E. Bocher, T. Leduc and G. Moreau. "Sensitivity of Spatial Indicators for Urban Terrain Characterization," In: IEEE International Geoscience \& Remote Sensing Symposium, IGARSS-2008, Boston, Massachusetts, U.S.A., 2008.

[41] E. Bocher, T. Leduc and F. González Cortés, "UrbSAT: from Spatial SQL to Urban Indicator Definition and Production," In: Free and Open Source Software for Geospatial Conference, FOSS4G'2008, Cape Town, South Africa, 2008.

[42] T. Leduc, E. Bocher and G. Moreau, "GDMS-R: A Mixed SQL to Manage Raster and Vector Data,” In: J. Horak, L. Halounova, D. Kusendova, P. Rapant, and V. Vozenlek, Eds., Advances in Geoinformation Technologies, Chapter 4, pp. 43-56. VSB-Technical University of Ostrava, Czech Republic, 2009.
[43] E. Bocher, T. Leduc, G. Moreau and F. Gonzalez Cortés, "GDMS: an Abstraction Layer to Enhance Spatial Data Infrastructures Usability,” In: 11th AGILE International Conference on Geographic Information Science, AGILE'2008, Girona, Spain, 2008.

[44] T. Leduc, E. Bocher, F. Gonzalez Cortes and G. Moreau. "GDMS: A Mixed Spatial Semantic to Enhance Urban Knowledge,” In: 1st ECN and Keio University Global COE Joint Workshop, Nantes, France, 2008.

[45] A. Léobon, "La Qualification des Ambiances Sonores Urbaines”, Revue Natures - Sciences - Sociétés. Vol. III, No. 1, pp. 26-41, 1995.

[46] A. Léobon, P. Woloszyn, M. Demais and E. Pasquier, A-V. Blain, "Identité Sonore et Qualité de vie en Centre Ville (Quartier Graslin, Nantes),” Rapport de Recherche SRETIE, Ministère de l'Environnement, pp. 124, 1994.

[47] A. Léobon, “Analyse Sensorielle d'un Environnement Sonore Urbain," Colloque L'Acoustique et la Ville, EAPLD, pp. 30-34, 1991.

[48] A. Léobon, "Qualification et Cartographie des Ambiances Sonores du Centre Historique Nantais," Rapport de Recherche Ville de Nantes, p. 186, 1995. 